\title{
PENGARUH KARAKTERISTIK INDIVIDU, MOTIVASI, KOMITMEN KERJA TERHADAP KINERJA GURU SMA SWASTA DI KOTA KENDARI (STUDI KASUS GURU SMAS MUHAMMADIYAH KENDARI, SMAS KARTIKA KENDARI, DAN SMAS IDHATA KENDARI)
}

\author{
Abdul Hamid \\ Program Studi Manajemen, Fakultas Ekonomi dan Bisnis Islam \\ Universitas Muhammadiyah Kendari \\ e-mail: abdul.hamid@umkendari.ac.id
}

\begin{abstract}
ABSTRAK: Penelitian ini bertujuan untuk menguji dan menganalisis : (1) pengaruh karakteristik individu terhadap motivasi guru SMA Swasta di Kota Kendari. (2) pengaruh karakteristik individu terhadap terhadap komitmen kerja guru SMA Swasta di Kota Kendari. (3) pengaruh motivasi terhadap komitmen kerja guru SMA Swasta di Kota Kendari. (4) pengaruh motivasi terhadap kinerja guru SMA Swasta di Kota Kendari. (5) pengaruh komitmen kerja terhadap kinerja guru SMA Swasta di Kota Kendari. Metode penelitian yang digunakan adalah metode penelitian deskriptif kuantitatif dengan teknik survei. Populasi penelitian ini adalah semua guru PNS di SMAS Muhammadiyah Kendari, SMAS Kartika dan SMAS Idata di Kota Kendari. Sampel penelitian ini sebanyak 69 guru yang diambil dengan menggunakan random sampling secara undian. Teknik pengumpulan data variabel karakteristik individu, motivasi, komitmen kerja dan kinerja guru digunakan teknik kuesioner. Teknik analisis data yang digunakan adalah uji $t$ dan regresi berganda. Hasil penelitian menunjukan bahwa : (1) Karakteristik individu berpengaruh positif terhadap motivasi, (2) Karakteristik individu berpengaruh positif terhadap komitmen kerja, (3) motivasi berpengaruh positif terhadap komitmen kerja, (4) motivasi berpengaruh positif terhadap kinerja, (5) komitmen kerja berpengaruh positif terhadap kinerja.
\end{abstract}

Kata Kunci: Karakteristik individu, Motivasi, Komitmen Kerja dan Kinerja.

Abstract: This study aimed to examine and analyze: (1) the effect of individual characteristic on the motivation of teachers at private senior high schools in Kendari city; (2) the effect of individual characteristics on the work commitment of teachers at private senior high schools in Kendari city; (3) the effect of motivation on the work commitment of teachers at private senior high schools in Kendari city; (4) the effect of motivation on the performance of teachers at private senior high schools in Kendari city; (5) the effect of work commitment on the performance of teachers at private senior high schools in Kendari city. The study employed a descriptive qualitative method by using the survey technique. The population of the study was all full-time teachers of SMAS Muhammadiyah of Kendari, SMAS Kartika, and SMAS Idata located in Kendari city. The samples of the study were 69 teachers which were determined by using the random sampling method, i.e. lottery. A questionnaire was used to collect data of individual characteristics, motivation, work commitment, and teacher's performance variables. The data were analyzed by conducting t-test and multiple regression analysis. 
The results of the study indicated that: (1) individual characteristics had a positive effect on motivation, (2) individual characteristics has a positive effect on work commitment, (3) motivation had a positive effect on work commitment, (4) motivation had a positive effect on performance, (5) work commitment had a positive effect on performance.

Keywords: Election Education, Teacher Politicization.

\section{PENDAHULUAN}

Pendidikan adalah sebuah usaha pembelajaran yang bertujuan untuk membentuk manusia yang merdeka (Feire, 1999: 9). Dalam konteks ini manusia yang lain berkapasitas intelektual tinggi, juga mempunyai tanggung jawab terhadap lingkungan sekitarnya. Ini berarti bahwa pendidikan mempunyai arti penting dalam membentuk wacana dan budaya masyarakat. Peningkatan mutu pendidikan dewasa ini merupakan suatu kebutuhan yang tidak dapat ditunda-tunda lagi. Keberhasilan pembangunan suatu bangsa ditentukan terutama oleh keberadaan sumber daya manusia yang berkualitas pula. Pengalaman pembangunan di Negara-Negara Asia seperti Jepang dan Taiwan, merupakan bukti sangat meyakinkan tentang sumber daya manusia dalam konteks pembangunan.

Guru yang memiliki kinerja yang baik adalah guru yang melaksanakan proses belajar mengajar dengan kualitas yang tinggi. Menurut Usman (2001:21) bahwa guru yang memiliki kinerja adalah guru yang memiliki kualitas dalam menyusun rencana program pengajaran, melaksanakan program pengajaran dan menyampaikan materi dengan baik.

Profesionalisme yang dimiliki guru dan baiknya motivasi dari pimpinan yang dimiliki oleh kepala sekolah dapat meningkatkan kinerja guru dalam melaksanakan tugasnya. Kinerja seorang guru sangat ditentukan oleh kemampuan Profesional yang dimiliki dalam menjalankan tugas. Menurut Mulyasa (2005 :13) bahwa kemampuan Profesional guru dalam menciptakan pembelajaran yang berkualitas sangat ditentukan keberhasilan Profesional yang tinggi adalah guru memiliki : (1) tanggung jawab terhadap profesinya, (2) memiliki kemampuan dalam merencanakan program pengajaran, (3) memiliki kemampuan melaksanakan pengajaran, (4) menguasai bahan pengajaran, (5) memiliki kemampuan melaksanakan evaluasi.

Keberadaan guru perlu diperhatikan agar motivasi mengajarnya semakin meningkat, sehingga mampu memberikan pelayanan dengan baik. Dewasa ini, eksistensi guru sebagai unsur pokok dalam proses pembelajaran, masih perlu ditingkatkan. Peningkatan ini mencakup berbagai aspek, yaitu meliputi : aspek peningkatan kualitas sumber daya manusia sehingga memenuhi kriteria sebagai guruyang Profesional, dan aspek peningkatan kesejahteraannya.

Pemerintah telah melakukan berbagai upaya dalam meningkatkan kesejahteraan guru, berupa : kenaikan gaji, kenaikan tunjangan guru, kenaikan honor kelebihan jam mengajar dan lain sebagainya. Namun demikian, upaya tersebut dirasakan masih belum mampu meningkatkan kesejahteraan guru, karena biaya untuk kebutuhan hidup sehari-hari semakin meningkat, sebagai akibat dampak krisis ekonomi yang berkepanjangan. Guru dengan penghasilan rendah, yang tidak cukup untuk memenuhi kebutuhan hidupnya, paksa oleh keadaan untuk berjuang mencari penghasilan tambahan. Dalam kondisi seperti itu, banyak guru terpaksa tidak dapat 
memberikan perhatian penuh terhadap pelaksanaan pekerjaan sebagia guru secara Profesional, karena waktunya banyak tersita untuk mencari penghasilan tambahan. Upaya mencari tambahan penghasilan ini berbagai kegiatan yang dilakukan, biasanya menjadi makelar, berkebun, bahkan tidka jarang menjadi tukang ojek, dan kegiatankegiatan lain. Guru-guru semacam itu, tentu saja akna tersita waktu dan konsitensinya dalam melaksanakan kompetensinya secara Profesional. Kondisi seperti itu, akan mengakibatkan citra guru dimata masyarakat sebagai pekerja mulia, abdi Negara dan abdi masyarakat akan semakin menurun dan tercemar.

Tuntutan global, semakin majunya teknologi pendidikan serta semakin tingginya tingkat persaingan lulusan Sekolah Menengah Atas (SMA) untuk meneruskan ke jenjang pendidikan yang lebih tinggi, terutama ke Perguruan Tinggi favorit atau ke lapangan kerja yang diharapkan, menuntut kepada para pengajar untuk bekerja secara lebih professional dengan berlandaskan kepada disiplin yang tinggi. Dengan disiplin yang tinggi diharapkan dapat meningkatkan kinerja guru.

Pengaruh karakteristik individu serta komitmen kerja yang baik harus dimediasi oleh peran motivasi untuk mencapai sukses dengan tujuan untuk berhasil dalam melaksanakan tugasnya yang berdasarkan pada suatu ukuran prestasi (kinerja) yang telah ditetapkan.

Selanjutnya fenomena yang terjadi pada guru SMA Swasta di Kota Kendari terlihat dari sikap dan tingkahlaku yang ditunjukan kehadirannya menurun dimana sering melimpahkan wewenang mengajarnya pada Guru Tidak Tetap (GTT) dan terkadang lebih mementingkan pekerjaan sampingan yang lain.

Menurut hasil penelitian yang telah dilakukan oleh Abdul Jamal (2007: 130) tentang hubungan antara motivasi kerja guru dan supervisi pendidikan dengan kinerja guru menunjukan bahawa ada hubungan yang positif dan sangat signifikan antara motivasi kerja guru dan pelaksanaan supervisi pendidikan oleh pengawa sekolah secara bersama-sama terhadap peningkatan kinerja guru. Hal ini berarti bahwa semakin tinggi motivasi seorang guru maka akan semakin tinggi pula kinerjanya, dimana hal ini pula sejalan dengan pendapat Herzberg yang disebut sebagai teori dan Higiene (MotivationHygeine Theory) yang menunjukan bahwa orang yang berpandangan positif terhadap tugas pekerjaannya, tingkat kepuasaannya biasanya tinggi atau kinerja akan tinggi pula. Sebaliknya jika orang berpandangan negative terhadap tugas pekerjaannya, maka di dalam diri mereka tidak ada kepuasan sehinggi kinerjanya akan turun (Siagian, 2002: 107). Namun fenomena yang terjadi saat ini pada guru SMA Swasta di Kota Kendari bahwa dengan motivasi yang diberikan berupa pemberian insentif, harapan, motif, kenaikan gaji, uang lauk pauk bahkan sertifikasi guru tetapi belum dapat meningkatkan kinerja.

Hal ini mengakibatkan tingkat kelulusan SMA Swasta di Kota Kendari menurun dengan nilai rata-rata yang rendah seperti kelulusan siswa SMAS Kartika Kendari pada tahun ajaran 2013 kemarin dengan nilai rata-rata 6,12. Fenomena yang lain seperti tingkat kelulusan siswa di SMAS Muhammadiyah Kendari pada tahun 2013 hanya 90,32\%, sedangkan tahun-tahun sebelumnya yaitu tahun 2012 tingkat kelulusan siswa adalah $100 \%$. 


\section{METODE PENELITIAN}

Disain penelitian yang digunakan adalah metode survei dengan pendekatan kuantitatif. Penelitian survei yang dimaksud adalah bersifat menjelaskan hubungan kausal dan pengujian hipotesis. Penelitian survei dapat digunakan untuk maksud (1) penjajagan (eksploratif), (2) deskriptif, (3) penjelasan (eksplanatori atau evaluasi), (5) prediksi atau meramalkan kejadian tertentu dimasa yang akan datang, (6) penelitian operasional, dan (7) pengembangan indikator-indikator sosial.

Jenis penelitian survei ini menfokuskan pada pengungkapan hubungan kausal antar variabel, yaitu suatu penelitian yang diarahkan untuk menyelidiki hubungan sebab berdasarkan pengamatan terhadap akibat yang terjadi, dengan tujuan memisahkan pengaruh langsung dan tidak langsung variabel penyebab atau variabel eksogen terhadap variabel akibat atau variabel endogen. Variabel sebab akibat tersebut adalah karakteristik individu $\left(\mathrm{X}_{1}\right)$, motivasi $\left(\mathrm{X}_{2}\right)$, komitmen kerja $\left(\mathrm{X}_{3}\right)$, dan kinerja guru $(\mathrm{Y})$. Maka variabel-variabel tersebut perlu didefinisikan sebagai berikut: a).Karakteristik individu (X1) yang dimaksud adalah karakteristik yang dimiliki oleh seorang guru (responden) yang dapat menentukan kematangan dalam menjalankan tupoksinya, dengan indicator: usia, pendidikan, masa kerja, dan status perkawinan, yang dinyatakan dengan skala Likert. B).Motivasi (X2) yang dimaksud adalah semangat kerja yang dimiliki oleh para guru (responden) dalam menjalankan tupoksinya, yang ditentukan oleh indikator: kebutuhan, dorongan, dan insentif, yang dinyatakan dengan skala Likert. c). Komitmen kerja (X3) yang dimaksud adalah konsistensi seorang guru dalam menjalankan tupoksinya melalui indikator: kesetiaan, kemauan, dan kebanggaan terhadap pekerjaannya, yang dinyatakan dengan skala Likert. d).Kinerja guru ( $\mathrm{Y}$ ) yang dimaksud adalah hasil kerja yang dicapai oleh seorang guru (responden) dalam menjalankan tupoksinya, yang dilihat melalui indikator: kuantitas, kualitas kerja, ketangguhan, dan tanggung jawab, yang dinyatakan dengan skala Likert.

Teknik analisis data menggunakan: a).uji validitas istrumen yaitu Uji validitas dilakukan berkenaan dengan ketepatan alat ukur terhadap konsep yang diukur sehingga benar-benar mengukur apa yang seharusnya diukur. Validitas adalah suatu ukuran yang menunjukan tingkat keandalan atau kesahihan suatu alat ukur. Alat ukur yang kurang valid berarti memiliki validitas rendah. Untuk menguji validitas alat ukur, terlebih dahulu dicari harga korelasi antara bagian-bagian dari alat ukur secara keseluruhan dengan cara mengkorelasikan setiap butir alat ukur dengan skor total yang merupakan jumlah tiap skor butir. b).uji reliabilitas instrument yaitu Uji reliabilitas dilakukan untuk mendapatkan tingkat ketepatan (keterandalan atau keajengan) alat pengumpul data (instrumen) yang digunakan. Uji reliabilitas instrumen dilakukan dengan rumus alpha.

\section{HASIL PENELITIAN DAN PEMBAHASAN}

Peneliti, dalam melakukan kajian telah melakukan pengujian sesuai metode penelitian yaitu:

1. Variabel Karakteristik Individu

Variabel ini dibentuk oleh 4 (empat) indikator, yaitu usia, pendidikan, masa kerja, dan status perkawinan. Setiap indikator memiliki 3 item pernyataan, sehingga variabel ini memilik 12 item penyataan, dengan deskripsi sebagai berikut: 
Tabel 1. Deskripsi Jawaban Responden Untuk Variabel Karakteristik Individu

\begin{tabular}{|c|c|c|c|c|c|c|c|c|c|c|c|c|}
\hline \multirow{2}{*}{$\begin{array}{c}\text { Item } \\
\text { Pernyataan }\end{array}$} & \multicolumn{2}{|c|}{ SS } & \multicolumn{2}{|c|}{$\mathrm{s}$} & \multicolumn{2}{|c|}{$\mathrm{N}$} & \multicolumn{2}{|c|}{ TS } & \multicolumn{2}{|c|}{ STS } & \multirow{2}{*}{ Total } & \multirow{2}{*}{$\begin{array}{l}\text { Rata- } \\
\text { Rata }\end{array}$} \\
\hline & $f$ & $\%$ & $\mathrm{~F}$ & $\%$ & $\mathrm{~F}$ & $\%$ & $f$ & $\%$ & $f$ & $\%$ & & \\
\hline $\mathrm{X} 1.1 .1$ & 27 & 39.13 & 31 & 44.93 & 7 & 10.14 & 1 & 1.45 & 1 & 1.45 & 283.00 & 4.10 \\
\hline $\mathrm{X} 1.1 .2$ & 15 & 21.74 & 28 & 40.58 & 24 & 34.78 & 0 & - & 0 & - & 259.00 & 3.75 \\
\hline \multirow[t]{2}{*}{$\mathrm{X} 1.1 .3$} & 22 & 31.88 & 28 & 40.58 & 17 & 24.64 & 0 & - & 0 & - & 273.00 & 3.96 \\
\hline & \multicolumn{10}{|c|}{ Rata-Rata } & & 3.94 \\
\hline $\mathrm{X} 1.2 .1$ & 52 & 75.36 & 9 & 13.04 & 4 & 5.80 & 2 & 2.90 & 0 & - & 312.00 & 4.52 \\
\hline $\mathrm{X} 1.2 .2$ & 16 & 23.19 & 43 & 62.32 & 4 & 5.80 & 4 & 5.80 & 0 & - & 272.00 & 3.94 \\
\hline \multirow[t]{2}{*}{$\mathrm{X} 1.2 .3$} & 11 & 15.94 & 53 & 76.81 & 3 & 4.35 & 0 & - & 0 & - & 276.00 & 4.00 \\
\hline & \multicolumn{10}{|c|}{ Rata-Rata } & & 4.15 \\
\hline $\mathrm{X} 1.3 .1$ & 16 & 23.19 & 37 & 53.62 & 13 & 18.84 & 1 & 1.45 & 0 & - & 269.00 & 3.90 \\
\hline $\mathrm{X} 1.3 .2$ & 6 & 8.70 & 39 & 56.52 & 21 & 30.43 & 1 & 1.45 & 0 & - & 251.00 & 3.64 \\
\hline \multirow[t]{2}{*}{$\mathrm{X} 1.3 .3$} & 3 & 4.35 & 54 & 78.26 & 8 & 11.59 & 2 & 2.90 & 0 & - & 259.00 & 3.75 \\
\hline & \multicolumn{10}{|c|}{ Rata-Rata } & & 3.76 \\
\hline $\mathrm{X} 1.4 .1$ & 27 & 39.13 & 33 & 47.83 & 7 & 10.14 & 0 & - & 0 & - & 288.00 & 4.17 \\
\hline $\mathrm{X} 1.4 .2$ & 8 & 11.59 & 33 & 47.83 & 25 & 36.23 & 1 & 1.45 & 0 & - & 249.00 & 3.61 \\
\hline \multirow[t]{3}{*}{$\mathrm{X} 1.4 .3$} & 19 & 27.54 & 32 & 46.38 & 15 & 21.74 & 1 & 1.45 & 0 & - & 270.00 & 3.91 \\
\hline & \multicolumn{10}{|c|}{ Rata-Rata } & & 3.90 \\
\hline & \multicolumn{10}{|c|}{ Rata-Rata Variabel X1 } & & 3.94 \\
\hline
\end{tabular}

Sumber : Data primer, diolah 2015.

2. Variabel Motivasi

Variabel motivasi dibentuk oleh 3 (tiga) indikator, yaitu kebutuhan, dorongan, dan insentif. Setiap indikator terdiri dari tiga item pernyataan, sebagaimana dideskripsikan pada tabel 2 berikut:

Tabel 2. Deskripsi Jawaban Responden Untuk Variabel Motivasi

\begin{tabular}{|c|c|c|c|c|c|c|c|c|c|c|c|c|}
\hline \multirow{2}{*}{$\begin{array}{c}\text { Item } \\
\text { Pernyataan }\end{array}$} & \multicolumn{3}{|c|}{ SS } & \multicolumn{3}{|c|}{ S } & \multicolumn{3}{|c|}{ N } & \multicolumn{2}{|c|}{ TS } & \multicolumn{2}{|c|}{ STS } & \multirow{2}{*}{ Total } & Rata- \\
Rata
\end{tabular}

Sumber : Data primer, diolah 2015.

3. Variabel Komitmen Kerja

Variabel komitmen kerja dibentuk oleh 3 (tiga) indikator, yaitu kesetiaan, kemauan, dan kebanggan. Setiap indikator kesetiaan terdiri dari tiga item pernyataan, sebagaimana dideskripsikan pada tabel 3 berikut: 
Tabel 3.Deskripsi Jawaban Responden Untuk Variabel Komitmen Kerja

\begin{tabular}{|c|c|c|c|c|c|c|c|c|c|c|c|c|}
\hline \multirow{2}{*}{$\begin{array}{c}\text { Item } \\
\text { Pernyataan }\end{array}$} & \multicolumn{2}{|c|}{ SS } & \multicolumn{2}{|c|}{$S$} & \multicolumn{2}{|c|}{$\mathrm{N}$} & \multicolumn{2}{|c|}{ TS } & \multicolumn{2}{|c|}{ STS } & \multirow{2}{*}{ Total } & \multirow{2}{*}{$\begin{array}{l}\text { Rata- } \\
\text { Rata }\end{array}$} \\
\hline & $\mathrm{F}$ & $\%$ & $\mathrm{~F}$ & $\%$ & $\mathrm{~F}$ & $\%$ & $f$ & $\%$ & $f$ & $\%$ & & \\
\hline X3.1.1 & 34 & 49.28 & 25 & 36.23 & 4 & 5.80 & 4 & 5.80 & 0 & - & 290.00 & 4.20 \\
\hline X3.1.2 & 24 & 34.78 & 36 & 52.17 & 3 & 4.35 & 3 & 4.35 & 1 & 1.45 & 280.00 & 4.06 \\
\hline \multirow[t]{2}{*}{ X3.1.3 } & 24 & 34.78 & 26 & 37.68 & 16 & 23.19 & 1 & 1.45 & 0 & - & 274.00 & 3.97 \\
\hline & \multicolumn{10}{|c|}{ Rata-Rata } & & 4.08 \\
\hline X3.2.1 & 40 & 57.97 & 18 & 26.09 & 9 & 13.04 & 0 & - & 0 & - & 299.00 & 4.33 \\
\hline X3.2.2 & 26 & 37.68 & 33 & 47.83 & 7 & 10.14 & 1 & 1.45 & 0 & - & 285.00 & 4.13 \\
\hline \multirow[t]{2}{*}{$\times 32.3$} & 36 & 52.17 & 24 & 34.78 & 6 & 8.70 & 1 & 1.45 & 0 & - & 296.00 & 4.29 \\
\hline & \multicolumn{10}{|c|}{ Rata-Rata } & & 4.23 \\
\hline X3.3.1 & 23 & 33.33 & 32 & 46.38 & 12 & 17.39 & 0 & - & 0 & - & 279.00 & 4.04 \\
\hline X3.3.2 & 16 & 23.19 & 33 & 47.83 & 17 & 24.64 & 1 & 1.45 & 0 & - & 265.00 & 3.84 \\
\hline \multirow[t]{3}{*}{ X3.3.3 } & 39 & 56.52 & 10 & 14.49 & 18 & 26.09 & 0 & - & 0 & - & 289.00 & 4.19 \\
\hline & \multicolumn{10}{|c|}{ Rata-Rata } & & 4.01 \\
\hline & \multicolumn{10}{|c|}{ Rata-Rata Variabel X3 } & & 4.12 \\
\hline
\end{tabular}

Sumber : Data primer, diolah 2015.

4. Variabel Kinerja Guru

Variabel kinerja guru dalam penelitian ini dibentuk oleh 4 (empat) indikator, yaitu: kuantitas kerja, kualitas kerja, ketangguhan, dan tanggung jawab. Setiap indikator dibentuk pula oleh 3 item pernyataan, sebagaimana dideskripsikan pada tabel 4. Berikut:

Tabel 4.Deskripsi Jawaban Responden Untuk Variabel Kinerja

\begin{tabular}{|c|c|c|c|c|c|c|c|c|c|c|c|c|}
\hline \multirow{2}{*}{$\begin{array}{c}\text { Item } \\
\text { Pernyataan }\end{array}$} & \multicolumn{2}{|c|}{ SS } & \multicolumn{2}{|r|}{$\mathrm{S}$} & \multicolumn{2}{|c|}{$\mathrm{N}$} & \multicolumn{2}{|c|}{ TS } & \multicolumn{2}{|c|}{ STS } & \multirow{2}{*}{ Total } & \multirow{2}{*}{$\begin{array}{l}\text { Rata- } \\
\text { Rata }\end{array}$} \\
\hline & $\mathrm{F}$ & $\%$ & $\mathrm{~F}$ & $\%$ & $f$ & $\%$ & $f$ & $\%$ & $f$ & $\%$ & & \\
\hline Y1.1.1 & 21 & 30.43 & 32 & 46.38 & 11 & 15.94 & 3 & 4.35 & 0 & - & 272.00 & 3.94 \\
\hline Y1.1.2 & 21 & 30.43 & 34 & 49.28 & 11 & 15.94 & 1 & 1.45 & 0 & - & 276.00 & 4.00 \\
\hline \multirow[t]{2}{*}{ Y1.1.3 } & 30 & 43.48 & 24 & 34.78 & 10 & 14.49 & 3 & 4.35 & 0 & - & 282.00 & 4.09 \\
\hline & \multicolumn{11}{|c|}{ Rata-Rata } & 4,01 \\
\hline Y1.1.4 & 15 & 21.74 & 36 & 52.17 & 10 & 14.49 & 5 & 7.25 & 1 & 1.45 & 260.00 & 3.77 \\
\hline Y1.2.1 & 28 & 40.58 & 28 & 40.58 & 10 & 14.49 & 1 & 1.45 & 0 & - & 284.00 & 4.12 \\
\hline \multirow[t]{2}{*}{$\mathrm{Y} 1.2 .2$} & 16 & 23.19 & 39 & 56.52 & 11 & 15.94 & 1 & 1.45 & 0 & - & 271.00 & 3.93 \\
\hline & \multicolumn{11}{|c|}{ Rata-Rata } & 3,94 \\
\hline Y1.2.3 & 36 & 52.17 & 26 & 37.68 & 4 & 5.80 & 1 & 1.45 & 0 & - & 298.00 & 4.32 \\
\hline Y1.2.4 & 31 & 44.93 & 32 & 46.38 & 3 & 4.35 & 1 & 1.45 & 0 & - & 294.00 & 4.26 \\
\hline \multirow[t]{2}{*}{ Y1.3.1 } & 29 & 42.03 & 31 & 44.93 & 5 & 7.25 & 2 & 2.90 & 0 & - & 288.00 & 4.17 \\
\hline & \multicolumn{11}{|c|}{ Rata-Rata } & 4,25 \\
\hline Y1.3.2 & 26 & 37.68 & 31 & 44.93 & 8 & 11.59 & 2 & 2.90 & 0 & - & 282.00 & 4.09 \\
\hline Y1.3.3 & 24 & 34.78 & 31 & 44.93 & 12 & 17.39 & 0 & - & 0 & - & 280.00 & 4.06 \\
\hline \multirow[t]{3}{*}{ Y1.3.4 } & 26 & 37.68 & 36 & 52.17 & 3 & 4.35 & 2 & 2.90 & 0 & - & 287.00 & 4.16 \\
\hline & \multicolumn{10}{|c|}{ Rata-Rata } & & 4.10 \\
\hline & & & & & Rat & Rata Y & & & & & & 4.07 \\
\hline
\end{tabular}

Sumber : Data primer, diolah 2015.

Data-data yang diperoleh sesuai tabel 1 sampai dengan tabel 4, kemudian di analisis sesuai metode penelitian, maka diperoleh hasil penelitian berupa:

1. Pengaruh Karakteristik Individu terhadap Motivasi

Variabel karakteristik individu yang terdiri dari tiga indikator yaitu usia, pendidikan dan kesehatan. Berdasarkan hasil pengujian penelitian menunjukan bahwa Standardizer regression weigh (koefisien jalur) pengaruh variabel karakteristik individu terhadap motivasi nilai koefisien jalur yang positif. Hal ini menunjukan bahwa karakteristik individu mempunyai pengaruh yang positif dan signifikan 
terhadap motivasi, ini membuktikan bahwa hipotesis $1\left(\mathrm{H}_{1}\right)$ yang menyatakan bahwa "terdapat pengaruh positif antara karakteristik individu $\left(\mathrm{X}_{1}\right)$ dengan motivasi $\left(\mathrm{X}_{2}\right)$ teruji kebenarannya. Karakteristik individu berpengaruh positif dan signifikan berarti bahwa setiap perubahan peningkatan indikator karakteristik individu searah positif dalam mempengaruhi peningkatan motivasi dan peningkatan karakteristik individu akan mempunyai arti/makna yang positif terhadap peningkatan motivasi.

2. Pengaruh Karakteristik Individu terhadap Kinerja

Berdasarkan hasil pengujian menunjukan bahwa nilai koefisien jalur berdasarkan Standadizer Regression Weights; (Group Number 1-Default model). Pengaruh karakteristik individu terhadap kinerja mempunyai nilai koefisien jalur yang positif. Hal ini membuktikan bahwa hipotesis $2\left(\mathrm{H}_{2}\right)$ yang menunjukan bahwa "terdapat pengaruh positif antara karakteristik individu $\left(\mathrm{X}_{1}\right)$ terhadap kinerja $(\mathrm{Y})$ terbukti sehingga hipotesis dapat diterima. Hasil penelitian menunjukan bahwa karakteristik individu berpengaruh positif dan signifikan terhadap kinerja ini berarti bahwa setiap perubahan peningkatan inadikator karakteristik individu melalui usia, pendidikan dan kesehatan searah atau bermakna dalam mempengaruhi kinerja ini berarti bahwa seseorang yang usianya semakin meningkat maka semakin matang dan berpengalaman dalam bekerja/mengajar serta semakin tingginya tingkat pendidikan seorang guru maka semakin tinggi pengetahuan dan kompetensi sehingga tujuan pembelajaran akan tercapai sesuai dengan isi kurikulum.

3. Pengaruh Motivasi terhadap Komitmen Kerja

Berdasarkan hasil pengujian penelitian menunjukan bahwa Standardizer regression weigh (koefisien jalur) pengaruh variabel motivasi terhadap komitmen kerja nilai koefisien jalur yang positif. Hal ini menunjukan bahwa motivasi mempunyai hubungan yang positif dan signifikan terhadap komitmen kerja. Hal ini membuktikan bahwa hipotesis $3\left(\mathrm{H}_{3}\right)$ yang menyatakan bahwa "terdapat pengaruh posistif antara motivasi $\left(\mathrm{X}_{2}\right)$ terhadap komitmen kerja $\left(\mathrm{X}_{3}\right)$. Dengan demikian hipotesis yang diajukan teruji kebenarannya yaitu motivasi berpengaruh positif dan signifikan berarti bahwa setiap peningkatan motivasi searah positif dengan peningkatan komitmen kerja setiap peningkatan motivasi akan mempunyai makna yang positif terhadap peningkatan komitmen kerja. Seorang guru yang memiliki komitmen kerja yang tinggi adalah menunjukan adanya kesetiaan terhadap pekerjaannya, adanya kemauan untuk melaksanakan tanggung jawab yang diembannya dan bangga terhadap pekerjaannya sehinga hal ini akan sangat mendukung peningkatan motivasi seorang guru.

4. Pengaruh Motivasi terhadap Kinerja

Berdasarkan hasil pengujian penelitian menunjukan bahwa Standardizer regression weigh (koefisien jalur) pengaruh variabel motivasi terhadap kinerja guru nilai koefisien jalur yang positif. Hal ini membuktikan bahwa motivasi mempunyai pengaruh yang positif dan signifikan terhadap kinerja. Hal ini menunjukan bahwa hipotesis $4\left(\mathrm{H}_{4}\right)$ yang menyatakan bahwa 'terdapat pengaruh positif antara motivasi $\left(\mathrm{X}_{2}\right)$ terhadap kinerja $(\mathrm{Y})$ teruji kebenarannya. Motivasi berpengaruh positif dan signifikan berarti bahwa setiap perubahan peningkatan indikator motivasi searah positif denga peningkatan kinerja, setiap peningkatan motivasi akan mempunyai arti/makna yang positif terhadap peningkatan kinerja. 


\section{Pengaruh Komitmen Kerja terhadap Kinerja}

Variabel komitmen yang terdiri dari empat indikator yaitu kesetiaan, kemauan, kebanggaan dan tanggung jawab. Berdasarkan hasil analisis hubungan antara variabel komitmen kerja dengan kinerja menunjukan bahwa regresision weight (koefisien jalur) pengaruh variabel komitmen kerja terhadap kinerja nilai koefisien jalur yang positif. Hasil ini memberikan makna bahwa variabel komitmen kerja yang terdiri dari kesetiaan, kemauan, kebanggaan dan tanggung jawab mempunyai pengaruh yang signifikan terhadap peningkatan kinerja.

Komitmen kerja mempunyai hubungan positif dan signifikan terhadap kinerja, artinya semakin tinggi komitmen kerja maka semakin tinggi pula kinerja, perubahan peningkatan indikator komitmen kerja searah positif dan signifikan terhadap peningkatan kinerja guru. Semakin setia seorang guru terhadap profesinya, semakin meningkat kemauan guru untuk bekerja, memiliki rasa bangga terhadap pekerjaannya dan semakin tingginya tanggung jawabnya dalam menyelesaikan tugasnya maka akan dapat meningkatkan kinerja seorang guru.

\section{KESIMPULAN}

Pengaruh karakteristik individu, motivasi, komitmen kerja dan kinerja Guru SMAS di Kota Kendari (survei pada SMAS Muhammadiyah Kendari, SMAS Kartika Kendari, dan SMAS Idata Kendari) yaitu: a).Karakteristik individu mempunyai pengaruh yang positif dan signifikan terhadap motivasi, artinya setiap perubahan indikator karakteristik individu dapat meningkatkan motivasi. Semakin baik karakteristik individu seorang guru maka motivasinya akan meningkat. b).Karakteristik individu mempunyai pengaruh yang positif dan signifikan terhadap kinerja, artinya setiap perubahan indikator karakteristik individu searah dengan peningkatan kinerja. Semakin meningkat karakteristik individu maka akan mengakibatkan semakin meningkatnya kinerja guru dalam melaksanakan setiap pekerjaan. c).Motivasi mempunyai pengaruh yang positif dan signifikan terhadap komitmen kerja, artinya semakin tinggi motivasi yang diimplementasikan melalui adanya dorongan yang kuat untuk melaksanakan tugas dapat meningkatkan komitmen kerja, perubahan peningkatan motivasi searah positif dan nyata terhadap peningkatan komitmen kerja. d).Motivasi mempunyai pengaruh yang positif dan signifikan terhadap kinerja, artinya semakin tinggi setiapa perubahan peningkatan motivasi yang diimplementasikan melalui adanya dorongan yang kuat untuk melaksanakan tugas dapat meningkatkan kinerja, perubahan peningkatan motivasi searah dan nyata terhadap peningkatan kinerja. e).Komitmen kerja mempunyai pengaruh yang positif dan signifikan terhadap kinerja, artinya setiapa perubahan peningkatan indikator komitmen kerja dapat meningkatkan kinerja, perubahan peningkatan komitmen kerja searah positif dan nyata terhadap peningkatan kinerja. f).Motivasi berperan sebagai mediasi pengaruh antara karakteristik individu berhubungan positif dan signifikan terhadap peningkatan kinerja. Artinya motivasi memiliki peran atau kontribusi yang kuat sebagai mediasi hubungan karakteristik individu dengan kinerja. Berhubungan positif dan signifikan artinya motivasi sebagai variabel antara berperan meningkatkan hubungan antara karakteristik individu kearah posistif dan signifikan terhadap peningkatan kinerja. 


\section{UCAPAN TERIMA KASIH}

Penulis mengucapkan terima kasih kepada Program Studi Magister Manajemen Program Pascasarjana Universitas Muhammadiyah Jakarta, yang telah mensuport dalam penelitian ini.

\section{DAFTAR PUSTAKA}

Asnawi, Erman. 2009. Pengaruh Motivasi dan Budaya Organisasi terhadap Kinerja yang dimediasi Sikap Kerja Pegawai pada Dinas Peternakan Kabupaten Konawe, Tesis. Universitas Haluoleo: Kendari.

Damayanti, Nia. 2010. Pengaruh Program Diklat dan Motivasi Kerja Terhadap Kinerja Guru, Tesis. UPI: Bandung.

Flippo, Edwin. B, 1993. Manjemen Personal (ter emahan), Edisi Keenam, Jilid I, Erlangga, Jakarta.

Gibson, James L. et. al. 1997. Organizations, Behavior, Structure, processes. $4 \mathrm{~h}$ ed, richardD. Irwinlnc.

Gibson, James. L, Ivancevich, Jhon M, Donnely JR, James H, 1996. Organisasi, Perilaku, Struktur, Proses, Edisi ke delapan, Binaputra Aksara: Jakarta.

Gitosudarmo, I, \& N. Sudito, 1997. Manajemen Bisnis, Penerbit BPFE Yogyakarta.

Handoko, 2000. Kinerja dan Tingkat Emosional, Pranata: Surabaya.

Herscoritch. 2001. Perilaku Organisasi. Citra Media: Bandung.

Huges et al., 1999. Motivation, Satisfaction and Performance Seem Clearly Related., New York: Academic Press.

Jamal Abdul Gani, 2007. Hubungan antara Motivasi Kerja Guru dan Supervise Pendidikan dengan Kinerja Guru (Survei pads SMP/MTs dan SMA/MA Negeri di Kabupateb Kolaka Tahun 2007). Tesis, Universitas Haluoleo: Kendari.

John Wiley \& Sons, Ltd. 2006. Journal of Organizational Behaviour "Work Performance, affective commitment, and work motivation: the roles of pay administration and pay level".

Latuanda. 2009. Analisis Pengaruh Karakteristik individu dan gaya Kepemimpinan Terhadap Kinerja Pegawai Melalui Perilaku Kerja Pada Sekretariat Daerah Kabupaten Konawe. Tesis. Universitas Haluoleo Kendari.

Locke, A.E., 1991. The Essence of Leadership. The Four Keys to Leading Successfully, Lexington Book, New York.

Luthans, Fred. 2002. Organizational Behavior, ninth edition. University of Nebraska.

M. Abdullah Alhadza, 2003. Pengaruh Motivasi Berprestasi Dan Perilaku Komunikasi Antarpribadi Terhadap Efektifitas Kepemimpinan Kepala Sekolah. Jurnal Pendidikan dan Kebudayaan, No. 040, Tahun ke-9, Januari 2003: Jakarta.

Mandailis, Irfan. 2010. Pengaruh Kepemimpinan dan Motivasi Kerja Terhadap Kinerja Guru, Tesis. UMJ: Jakarta.

Mangkunegara, 2005. Manajemen Sumber Daya Manusia. Penerbit Remaja Rosdakarya, Bandung.

Manullang Manihot. 2001. Manajemen Sumber days Manusia. Yogyakarta BPFE. Yogyakarta. 
McClelland, David C. Et al. 1994. The Achievement Motive, New York Irvington, Publisher.

Mitchell, 1982. Manajemen Era Baru. Mandar Maju: Bandung.

Moekiat, 2000. Fungsi Fungsi Manajemen. Penerbit Mandar Maju: Bandung.

Mohyi, Ach. 1999. Teori dan Perilaku Organisasi. Rajasa: Surabaya.

Mowday R.T., and Porter, L.W and Steers, R.M. 1992. Employee Organization Linkages:

The Psychology of Commitment, Absenteism and Turn Over, Academic, inc, London.

Mulyasa, E (2005). Implementasi Kurikulum 2004. PT. Remaja Rosdakarya Bandung.

Nawawi, Handari. 2001. MSDM untuk Bisnis yang Kompetitif. Gajah Mada University Press: Yogyakarta.

Nimran, Umar. 2004. Perilaku Organisasi. Citra Media: Surabaya.

Oemar Hamalik, 2000. Pengembangan Sumber Daya Manusia, Manajemen Pelatihan Ketenagakerjaan. Penerbit Bumi Aksara: Jakarta.

Rafiuddin, H. 2009. Pengaruh Implementasi Fungsi MSDM dan Motivasi Kerja terhadap Komitmen Kerja dan Kinerja Pegawai Administrasi pada Rektorat Unhalu. Tesis 5.2. Universitas Haluoleo: Kendari.

Rebecca, M. Sauders. 2006. Strategi Penilaian Kinerja Karyawan. Erlangga Jakarta.

Riduwan. 2004. Metode dan Teknik Menyusun Tesis. Alfabeta: Bandung.

Riduwan. 2004. Skala Pengukuran Variabel-Variabel Penelitian. Alfabeta Bandung.

Robbins, Stephen. P, 1996. Perilaku Organisasi, Jilid I dan II, Edisi Kedelapan, PT. Prenhallindo : Jakarta.

Robbins,S.P. 1996. Essentials of Organizational Behavior, New York: Prentice Hall. Internasional, Inc.

Schermerhorn, Jr. John R., 1991. Manajemen. Buku 2, Edisi Bahasa Indonesia, Cetakan Pertama, Diterjemahkan oleh Parnawa Putranta, Surya Dharma Ginting, SheelyanaJunaedi dan Diah Wudiastuti. Andi: Yogyakarta.

Sentot Wahjono Imam. 2009. Perilaku Organisasi. Graha Ilmu: Surabaya.

Setiati A. Dian. 2002. Strategi Organisasi: Perbedaan Produktivitas dan Kepuasan Organisasional, Teori Motivasi Abraham Maslow. Cetakan Kesatu. Amara Books.

Siagian, Sondang P. 2002. Kiat Meningkatkan Produktivitas Kinerja. PT. Rineka Cipta : Jakarta.

Sihotang, 2007. Manajemen Sumber days manusia. PT. Pradnya Paramita Jakarta. Singarimbun, Masri dan Effendi. Sofyan Ed. 1995. Metode Penelitian Survey. LP3ES : Jakarta.

Soedarmayanti, 2007. Manajemen Sumberdaya Manusia Reformasi Birokrasi dan Manajemen PNS. PT. Refika Aditama.

Soeprihanto, 1996. Penilaian Pelaksanan Pekerjaan dan Pengembangan Karyawan. BPFE: Yogyakarta.

Steers, RM and Porter, L. W., 1983. Motivation and Work Behavior, New York: Accademic Press.

Sudjana. 2002. Metode Statistika, Edisi ke -6. Tarsito: Bandung.

Sugiyono. 2004. Statistik Untuk Penelitian. Alfabeta: Bandung.

Suparji. 2009. Hubungan antara kepemimpinan dan Motivasi Berprestasi Guru dengan 
Kinerja Guru SMP/Madrasah Tsanawiyah di Kecamatan Pomalaa. Kabupaten Kolaka. Tesis 5.2. Universitas Haluoleo: Kendari.

Tarimana Roslina. 2009. Pengaruh Motivasi Kerja terhadap Kepuasan Kerja dan Prestasi Kerja Pegawai Di Lingkungan Unhalu Kendari. Tesis 5.2. Universitas Haluoleo: Kendari.

Terry, George R. 2003. Prinsip-Prinsip manajemen. PT. Bumi Aksara: Jakarta.

Timpe, 1999. Seri Manajemen Sumber Daya Manusia (Alih Bahasa Susanto Budidharma). Elex Media Komputindo: Jakarta.

Timpe, A.D, 1991. Motivasi Pegawai (Alih Bahasa Susanto Budidharma). Elex Media Komputindo: Jakarta.

Titop, H. Herman. 2009. Analisis Pengaruh Karakteristik Individu dan Pengembangan Karir terhadap Kepuasan Kerja dan Kinerja PNS pada Kantor Bupati kabupaten Konawe di Unaaha. Tesis 5.2. Universitas Haluoleo: Kendari.

Toner, James A.F. and Charles Wankel. 1986. Management, Third Edition. Prentice Hall International, Inc. Englewood Cliffs. New Jersey.

Usman, Muh. Uzer. 2001. Menjadi Guru Profesional. PT. Remaja Rosda Karya Bandung. West, 1997. Organizational Behaviour and Personnel Psychology, Penerjemah Muh. Shobaruddin. Rineka Cipta: Jakarta. 